\title{
BORDERS AND THE CITY: INTRA-URBAN BOUNDARIES IN GUANGZHOU (CHINA)*
}

\author{
WERNER BREITUNG \\ Sun Yatsen University, School of Geography and Planning, Guangzhou, People's Republic of China
}

Manuscript received November 3, 2011

Revised version November 7, 2011

\begin{abstract}
BREITUNG W., Borders and the city: Intra-urban boundaries in Guangzhou (China). Quaestiones Geographicae 30(4), Bogucki Wydawnictwo Naukowe, Poznań 2011, pp. 55-61. DOI 10.2478/v10117-011-0038-5, ISBN 978-83-6266288-3, ISSN 0137-477X.
\end{abstract}

АвSTRACT. Borders are fundamental structuring elements of space. This paper uses concepts derived from the study of political boundaries to make sense of urban structures and developments. It does this in the case of Guangzhou, a mega-city in Southern China, but the suggestion is that this approach is significant beyond the Chinese case. The author introduces five different ways to see borders (political, physical, socio-spatial, psychological and functional), and holds that border analysis should combine those five aspects. In the case of Guangzhou, spatially differentiated urban governance is seen as creating strong physical, social and other boundaries. This finding is illustrated by various pieces of evidence from the author's fieldwork, including survey data and qualitative interviews.

KEY WORDS: borders, Chinese city, urban governance, gated community, Guangzhou

Werner Breitung, Sun Yatsen University, School of Geography and Planning, 135 Xingang Xi Lu, Guangzhou 510275, China; e-mail: breitung@gmail.com

\section{Introduction}

This paper is about borders within a city. It looks at what exactly borders (or boundaries) are, how they define and structure urban space, and what they mean for people. In his famous book The image of the city, Kevin Lynch (1992) identified paths, edges, nodes, districts and landmarks as the key elements of urban space. His analysis has become widely cited and influential in the field of urban design. However, Lynch can be criticised for focusing too much on physical structures rather than seeing cities as extremely complex social, economic and political phenomena. In using the political geography term, borders, for what he called edges, this paper picks out one of his crucial elements and tries to give more depth and additional dimensions to it. In particular, it takes a rather innovative approach to delve into the border study literature to see how it can help us make sense of urban structural issues.

This literature has been rapidly growing in quantity and analytical quality since the 1990s. It is, however, very much restricted to the chang-

* The paper is an outcome of research funded by the German Science Foundation (DFG) with grants number BR 3546/1-1 and BR 3546/1-2. The author wants to thank all contributors to this project, especially Michael Arri, Zhu Yushu and Feng Dan, who did most of the fieldwork. 
ing nature and impact of national boundaries, and barely perceived outside the realm of political geography and geopolitics. This is a pity, because the findings and concepts of this research on borders have much to offer to geography in general - and as is argued here, to urban geography in particular. Borders are a spatial phenomenon, a structural element of space, and their relevance reaches beyond national borders and beyond their political aspect. The author has developed a framework of five aspects of borders, or approaches to border research, which is applied below to the study of Chinese urban space.

\section{Walking in Chinese cities}

The best way to understand cities, besides the study of maps, is to take a stroll and to observe attentively. While maps provide a birds-eye overview, on-the-ground observation adds both the third dimension and the human element. There is a literature in geography referring to $\mathrm{C}$. Baudelaire's and W. Benjamin's concept of the flâneur (e.g. Huang 2004), which takes subjective impressions of an aimlessly wandering person in an urban setting as the starting point to grasp crucial characteristics of places. When walking through Chinese (and in fact most East-Asian) cities, one observation is a cellular structure of neighbourhoods, often separated by big roads. Both administratively and physically, the people live in clearly bounded spaces which consequently are also represented on their mental maps. Due to an administrative structure of wards or street offices and residents' committees, the limits of the neighbourhoods are fixed and commonly known. The second observation, especially in China, is the abundance of walls and fences. This is true of traditional places such as the Beijing traditional alleyways (hutongs), but also of the socialist work units and post-socialist commercial housing estates, which tend to take the form of gated communities. More often than not, an attempt to cross one of the typical megablocks in Chinese cities ends at a wall or fence inside the block, and the flâneur finds himself in a semi-public residential space or at a gate to it. Finally, a third observation in Chinese cities is the socio-spatial separation especially of migrant workers, but increasingly also of the nouveau riches in urban space. As we wander through the cities, we encounter both migrant enclaves and high-class estates. These three observations set the scene for the discussion of intra-urban borders and for the five dimensions of analysis: physical, administrative, social, functional, and mental.

\section{Conceptualisation of borders}

The border literature in political geography and geopolitics mainly concentrates on the national level. National borders are examined at the national and supranational scale, but in the case of border regions, border landscapes and border communities, also at the local level (Wilson \& Donnan 1998, Papademetriou \& Meyers 2001, Breitung 2007, 2009a, 2009b). Borders separate nations and territories, but they also divide local space in border regions and border cities. This is especially apparent in enclaves such as Hong Kong or Singapore, and in divided or twin cities such as Jerusalem, Nicosia, pre-1990 Berlin or cities along the US-Mexican border. These cases involve international borderlines within cities.

However, urban space, not only in these special cases, is always made up of various boundaries created by administrative decisions, by processes of social or cultural segregation, by urban design, or by the mental representation of space as evident in imaginations, identities and human activity spaces. Urban research is widely engaged in the understanding of such boundaries, but often without explicit reference to the term, and generally without reference to the field of border studies in political geography.

Since the 1990s, the outputs of border studies have not just expanded in terms of quantity, but there has also been significant progress with regard to their theoretical value (Newman 2003, Kolossov 2005, Brunet-Jailly 2005). There is now an understanding of boundaries as socially constructed and dynamic spatial features. The existence, location and impact of borders must be understood as outcomes of social processes of bounding or border-drawing (van Houtum \& van Naerssen 2002). Newman $(2002,2003)$ emphasised these processes and called for the ex- 
amination of bounding practices rather than borderlines. Borders as social constructs must be interpreted as expressions of specific political, socio-economic and cultural circumstances. Such a process-based view of borders also implies that borderlines and border regimes are subject to changes in political, socio-economic and cultural circumstances. Their location and especially their character, openness and impacts are constantly renegotiated. Many national borders have lost their previous importance, and inversely - local boundaries, for example of gated communities, development zones and tourist resorts, have emerged. Driven by forces of globalisation, the difference between such boundaries and national ones is getting less fundamental (Sidaway 2007). In China, special economic and development zones are intra-urban bounded spaces following global logic, while the borders of Hong Kong and Macau are gradually moving from national to municipal status (Breitung 2002, 2007).

Earlier border discourses, especially in Europe, have often emphasised the divisive character of borders and the need to overcome and remove them. However, it has now become more obvious that borders do have functions. They protect, ensure control, allocate power, facilitate administration, and foster identities. The study of borders must include an analysis of those functions and consider possible conflicts of interest, as the functions are of different importance between different actors and between the different sides of the border.

Lastly, borders, beyond their functions and physical impacts, also carry meanings for people's identities and daily lives. They may emotionally be related to feelings of safety and 'home' on the one hand, and to unwelcome sentiments of enclosedness or exclusion on the other. The existence of borders is crucially based on their representation in people's minds.

These thoughts provided a conceptual basis for border studies, not only at the national level, but at all geographic scales where borders exist, including those within cities. A framework for a scale-independent analysis of boundaries should consider five different but interrelated aspects of borders and investigate them using a combination of the following approaches (Breitung 2002, 2007):
1) Political approach: Borders are manifestations of political and administrative territoriality. They demarcate spheres of influence and responsibility, and separate different governance spaces from each other. A political approach therefore requires an analysis of governance and power structures. Important related research areas are international relations and cross-border governance. Relevant issues with regard to urban boundaries are district (e.g. school or electoral district) boundaries and metropolitan regional governance.

2) Physical approach: Borders are visible in the landscape, both as physical structures such as fences and walls, and as discontinuities of land-use, building style, signage, vegetation, colours, or plot sizes. Border-landscape analysis can involve remote-sensing as well as onthe-ground survey methods. At the city level, urban morphology has always dealt with boundaries in urban space, as have urban designers (see for example Lynch's emphasis on "edges", or neighbourhood concepts for new towns, or the more recent debates about gated communities).

3) Socio-spatial approach: Borders are not only a physical, but also a social issue, both as socio-economic and socio-cultural division lines. Major debates turn around borders of wealth at the US-Mexican border, the Eastern and Southern borders of the EU and - closer to our case - the border between Hong Kong and mainland China. The cultural aspect plays a role in ethnic enclaves such as Nagorno Karabakh, and in cases of ethnic border-drawing such as in former Yugoslavia, Cyprus and Israel. Socio-spatial boundaries are made visible by spatial analysis of census and survey data. Ethnographic research can add more insights. In urban geography, socio-spatial borders are not a novel issue either. The vast literature on social segregation is basically about socio-economic and socio-cultural or racial boundaries within the city.

4) Psychological approach: Borders may be visible on maps and in landscapes, but as mentioned above, they also have an invisible aspect - their representation in people's minds. Psychological borders together with spatialised identities and the sense of belonging are 
important both at the national and the intraurban scale. Ethnographic interviews and the drawing of mental maps can bring the borders in people's minds to the fore. In urban geography, this can contribute to the understanding of neighbourhood boundaries and spatial behaviour (e.g. shopping routes).

5) Functional approach: In a space of flows and networks, borders are conceptualised not as edges of areas or territories, but as discontinuities, barriers or filters of flows and networks. In international border research, this approach is mostly employed by economic geographers studying the roles of cross-border resources and trade flows and of cross-border production networks. It can also be applied to personal networks and cross-border mobility. At the urban scale, this approach is reflected in research into activity spaces, social and functional networks, and time geography.

As can be seen from this short introduction, each of the five approaches is not entirely new in urban geography. The purpose of this paper is to suggest a more explicit use of border-research concepts and to advocate the combination of the above approaches. Research on urban social segregation, for example, can benefit from the incorporation of mental boundaries, social networks and differentiated governance; and debates on public space and the rights to the city should involve all five approaches.

And two last remarks about the use of the terms 'border' and 'boundary': First, no significant difference is made between these terms, as they are used almost synonymously in everyday life. Second, in advocating a broadened concept of borders (or boundaries), we should not mistake broad for imprecise and ambiguous. This paper will not include non-spatial borders such as social, class or gender boundaries, or language barriers, unless they are manifested in space. Borders are explicitly understood as dividing lines in space and not in other, more metaphorical ways.

\section{Chinese urban space}

Before turning to our own findings in Guangzhou, a brief summary of the different development trajectories of urban space in China seems necessary. It will include references to the role of boundaries and to the specific situation in Guangzhou. The latter is necessary because it is often overlooked that Chinese cities do indeed differ a lot from each other, and because many existing accounts refer to northern Chinese cities and are thus only partially useful for our case.

It should also be noted that, although Chinese cities have existed for thousands of years, China has not been very urbanised until recently. Most Chinese have grown up in the countryside, and only a small percentage of today's urbanites have urban family roots dating back to pre-socialist times. This of course affects the inheritance of traditional urban structures and to some extent the relevance of deeply historical references.

The traditional Chinese city was bounded by walls and gates, not only separating the inside from the outside, but also dividing the space inside into several wards. The ideal of a well-structured, rectangular and warded city is documented since the Zhou dynasty (around 1100 to $256 \mathrm{BC}$ ). At the same time, and less documented by annalists, unplanned 'abscesses' of cities grew outside the city walls. The official city inside the walls was the administrative, ritual and cultural headquarters of its region. Outside were the merchants, the suppliers, caterer, distributors and maintainers - those who kept the city running - although only the planned and ordered centre of administration, power and control was considered as 'the city'. The further south the cities were, the farther away from the ideological centre, the less strictly the planning guidelines were followed. The Pearl River Delta was strongly influenced by South and Southeast Asian architecture. The qilou, the archetypical old houses in Guangzhou with shops on the ground floor and the upper floors as living quarters, were not introverted like the northern Chinese courtyard houses, but open to the street. As a city of commerce, Guangzhou has always had a more public cityscape than northern cities. Many old citizens recall that governmental complexes or rich people's houses were surrounded by walls, but most entrances opened onto the public street. However, a cellular system of governance and social life was typical of all Chinese cities, including those in the South.

After 1949, most of the existing urban housing was turned to municipal housing bureaus (Wang 
1992). Street offices and residents' committees were established to facilitate ideological, political and social control at the neighbourhood level (Wu 2005). Many neighbourhoods were enclosed by gates, yet with loose access control. More importantly, the socialist period brought the introduction of the work unit (danwei) as an integral part of the new system of socialist production (Bjorklund 1986). The danweis, industrial or administrative, built integrated compounds comprising work places, housing, and social infrastructure. It can be said that for many work unit members, there was not much need to communicate beyond their compound (Gaubatz 1999). Even though the erection of walls was initially viewed as a waste of building material, most work units found ways to divert resources towards securing their boundaries in order to protect their mobile assets and to control access. As a consequence, the socialist Chinese city was dominated by walled compounds which were quite autonomous in their dealings inside and only loosely connected with each other. All around Guangzhou, many administrative, educational and industrial danwei compounds were set up, since the provincial capital particularly benefited from the hierarchical socialist resource allocation system (Lin 1999). Even the differentiation between well-equipped central- and provincial-level work units and poorer local ones reflected this hierarchical system. The desire to protect one's own unit's resources resulted in various bounding practices and a lack of overall urban planning.

While until the 1980s the work unit and street office neighbourhoods were the dominant sociospatial building blocks of Guangzhou and Chinese cities in general, this changed with Deng Xiaoping's market-oriented reforms in the 1980s and 1990s. Housing was then turned into a tradable commodity. First, the production side became marketised as work units commissioned newly established real estate companies to build housing estates for their staff. From 1998 on, the consumption side followed. Existing residential units were then privatised and new estates later built almost exclusively commercially. Commodity housing estates, or xiaoqu (literally, "small districts"), which almost all take the form of gated communities, have appeared both in the suburbs and on urban redevelopment sites (Miao 2003,
Xu 2008, Zhu et al. 2012). Mainly due to the influence of Hong Kong, the Pearl River Delta (including Guangzhou) was the first region in China to embrace market reforms, to develop commodity housing estates, and to see them becoming the dominant form of urban housing.

Throughout these different phases, the conditions of urban development have more than once changed fundamentally, but the cellular urban structure and the existence of boundaries seem to be a continuity throughout all change. Several authors have commented on the striking trajectory from walled city to work unit compound to gated community, without really being able to determine a path dependency (Münch 2004, Kögel 2004, Wu 2005). Given the differences in the modes of space production, the continuity should not be overemphasised, but the inherited cellular structure in urban governance and social belonging has certainly helped to accept both the work unit and the modern housing estate, while previous experiences of living in bounded compounds have supported the strong acceptance of gated communities in China.

\section{Intra-urban boundaries in Guangzhou}

From the above account it becomes apparent that the neighbourhood is an important level for urban governance in China, and most crucially that this neighbourhood governance has become spatially differentiated in many ways (Breitung 2012). The proliferation of commodity housing estates has partly replaced state institutions by private property management companies, effectively turning neighbourhood governance into a commercial activity paid by the property owners or residents. Some differences notwithstanding, this could be compared to forms of private urban governance in gated communities in the west. At the same time, street offices, residents' committees and work units still function as main actors in other neighbourhoods. Another very different mode of neighbourhood governance is practised in urbanised villages (or urban villages, or villages-in-the-city). These are former villages which have been physically incorporated into the fast-growing city, but still have control over their 
land and enjoy some degree of self-governance with village-based institutions and practices still in place.

These different governance modes are implemented at the same time in different neighbourhoods of the same city. This creates bounded governance spaces and significant intra-urban borders. Going back to the five categories introduced earlier, this argument follows the political approach: the appearance of intra-urban boundaries is explained by administrative territoriality and different power structures. However, the same boundaries are also physically, socially, mentally and functionally relevant.

Especially gated communities have strong physical borders. Access to public spaces such as residential greenery is restricted to residents and their guests, and thus implicitly to certain social groups. For the sake of efficiency, most estates are rather large, which affects the walkability of the city - and for some suburban mega-estates even the circulation of automobiles. Despite those inconveniences, a vast majority of interviewees in our fieldwork demanded such physical boundaries. In a survey of 662 residents in three gated communities in Guangzhou, we found that only $7.6 \%$ of them preferred a more relaxed gating mode, and only $0.9 \%$ favoured totally free access. By contrast, as many as $64 \%$ of those gated-community residents preferred an even stricter access control. Even the suggestion that the number of entrances might be increased was rejected by over $80 \%$ of the respondents. Qualitative interviews inside and outside the estates confirmed that the acceptance of the physical boundaries was high on both sides. We even heard that the residents of the adjacent urbanised village wished for the introduction of gates to it as well (for details, especially of the reasons for the reported attitudes, cf. Breitung 2012).

The differentiation of governance also comes with increasing social segregation. While during the socialist period members of a danwei used to live together in a compound regardless of their job position, there is now an exodus of the middle and upper classes to the new commodity housing estates, which in turn also changes the traditional neighbourhoods. At the same time, migrant enclaves mushroom in the urbanised villages, because their governance mode is flexible enough to provide housing outside the official urban channels. Thus, governance borders turn into social borders. Asked for their view on this kind of segregation, $43 \%$ of our respondents gave a positive opinion and only $23 \%$ a negative one.

These social and physical borders also act as psychological barriers. Our interviews showed that the former villages are often stigmatised as dirty, unruly and inhabited by people of lower 'quality' (suzhi). On the other hand, village residents described the commodity housing estates as a foreign 'fancy world' which was partly admired and partly ignored, but definitely distinct from their place. The physical gates play a very particular role as manifestations of the mental borders. As one respondent in our interviews said: "Walls give me a sense of territory, of (...) a place I feel like belonging to. Just like our garden, its doors may not have any practical use, but it makes me feel it is my place", and "once I step into (the estate), I immediately feel at home, being outside is like being on the way".

Lastly, physical and psychological borders are also functionally reflected in uneven flows of people and an uneven distribution of social networks. The gates work as filters or semi-permeable membranes rather than barriers. Flows are controlled, restricted to 'insiders' and - crucially in China - reduced. Miao (2003) characterises Chinese gated communities as "deserted streets in a jammed town". Significant impacts are also notable on intra-urban social networks, which raises the question of whether these borders lead to the disintegration of the city, to the falling apart of the urban society, and the fragmentation of urban space.

\section{Conclusion}

The last remarks call to mind the growing literature on urban fragmentation and splintering urbanism (e.g. Graham \& Marvin 2001). What this paper tries to add to this and other bodies of literature is an analytical tool: the identification and a comprehensive study of borders in space. With the integration of its five aspects, this approach may help to structure and deepen our understanding of urban structures and developments such as fragmentation and segregation. 
Even though the findings of our research are specifically about Chinese cities, or even just about Guangzhou, the approach itself is not. In other regional contexts, the outcomes will be different if there are no work units, no urbanised villages and less cellular societal traditions. However, there will be other boundaries, e.g. racial boundaries, no-go areas of crime, or bounded leisure and shopping spaces. The demonstrated approach offering a comprehensive understanding of intra-urban boundaries will still be valuable to the study of such places.

\section{References}

Bjorklund E.M., 1986. The Danwei: Socio-spatial characteristics of work units in China's urban society. Economic Geography, 62: 19-29.

Breitung W., 2002. Transformation of a boundary regime: The Hong Kong and Mainland China case. Environment and Planning, A 34: 1749-1762.

Breitung W., 2007. Overcoming borders, living with borders. Macao and the integration with China. Instituto Cultural do Governo da R.A.E. de Macau, Macau.

Breitung W., 2009a. Macau residents as border people. A changing border regime from a socio-cultural perspective. Journal of Current Chinese Affairs, 38(1): 101-127.

Breitung W., 2009b. Cities and borders - an introduction. Review of Culture, 30: 6-17 (bilingual English and Portuguese).

Breitung W., 2012. Enclave urbanism in China - attitudes towards gated communities in Guangzhou. Urban Geography, 33 (in print).

Brunet-Jailly E., 2005. Theorizing borders - an interdisciplinary perspective. Geopolitics, 10: 633-649.

Gaubatz P., 1999. China's urban transformation: patterns and processes of morphological change in Beijing, Shanghai and Guangzhou. Urban Studies, 36: 1495-1521.

Graham S. \& Marvin S., 2001. Splintering urbanism: Networked infrastructures, technological mobilities and the urban condition. Routledge, New York.

Huang T.-Y., 2004. Walking between slums and skyscrapers. Illusions of open space in Hong Kong, Tokyo and Shanghai. Hong Kong University Press, Hong Kong.
Kögel E., 2004. Von der Nachbarschaft zur Gated Community? Planungsprinzipien der Stadt in der VR China (From neighbourhood to gated community? Urban planning principles in the PR China). Trialog, 81: 40-43.

Kolossov V., 2005. Border studies - changing perspectives and theoretical approaches. Geopolitics, 10: 606-632.

Lin G.C.S., 1999. State policy and spatial restructuring in post-reform China, 1978-95. International Journal of Urban and Regional Research, 23(4): 670-696.

Lynch K., 1992. The image of the city. 21th ed. MIT Press, Cambridge.

Miao P., 2003. Deserted streets in a jammed town - the gated community in Chinese cities and its solution. Journal of Urban Design, 8: 45-66.

Münch B., 2004. Verborgene Kontinuitäten des chinesischen Urbanismus (Hidden continuities of Chinese urbanism). Archplus, 168: 44-49.

Newman D., 2002. Boundaries. In: Agnew J. et al. (eds), A companion to political geography. Blackwell, Malden: 123-137.

Newman D., 2003. On borders and power: A theoretical framework. Journal of Borderlands Studies, 18(1): 13-25.

Papademetriou D. \& Meyers D.W. (eds), 2001. Caught in the middle. Border communities in an era of globalisation. Carnegie Endowment for International Peace, Washington DC.

Sidaway J., 2007. Enclave space: a new metageography of development? Area, 39(3): 331-339.

van Houtum H. \& van Naerssen T., 2002. Bordering, ordering and othering. Journal of Economic and Social Geography (TESG), 93(2): 125-136.

Wang Y.P., 1992. Private sector housing in urban China since 1949: The case of Xi'an. Housing Studies 7(2): 119-137.

Wilson T. \& Donnan H. (eds), 1998. Border identities: Nation and state at international frontiers. Cambridge University Press, Cambridge.

Wu F., 2005. Rediscovering the "gate" under market transition: From work-unit compounds to commodity housing estates. Housing Studies, 20(2): 235-254.

Xu F., 2008. Gated communities and migrant enclaves: The conundrum for building "harmonious community/ shequ". Journal of Contemporary China, 17: 703-720.

Zhu Y., Breitung W. \& Li S.-M., 2012. The changing meaning of neighbourhood attachment in Chinese commodity housing estates: Evidence from Guangzhou. Urban Studies, 49 (in print). 